\title{
No paraíso da tecnologia, o consumidor vai às compras: plasma ou LCD?
}

\author{
Wellington Pereira* \\ José Felipe Almeida ${ }^{* *}$ \\ Walter Tadabiro Shima ${ }^{* *}$
}

A cada quatro anos ocorre o maior e mais aguardado evento futebolístico: a Copa do Mundo. Alguns articuladores de opinião dirão que a conquista desse importante troféu ou cálice (copa, em espanhol) servirá como pão, alimento, que embriaga e satisfaz aos torcedores. Sobretudo, no que diz respeito às grandes massas que tenderiam a deixar passar despercebidos eventos de ordem social, política e econômica - tema bastante recorrente quando relembrada a ditadura, em prática no Brasil, na conquista da Copa, em 1970. Ademais, essa competição esportiva desempenha papel de destaque no inebriamento dos indivíduos no que tange aos efeitos que podem ser observados sobre o padrão de consumo no período prévio e de ocorrência desse evento mundial ${ }^{35}$. A criação dessa nova atmosfera propícia ao consumo em torno da Copa do Mundo do Futebol é um dos maiores instrumentos de marketing relacionados a competições esportivas.

Nesse contexto, as lojas revendedoras de bens eletroeletrônicos procuram obter faturamentos superiores aos conquistados em outros períodos normais, principalmente, com relação à venda de televisores. Sobretudo no Brasil, já é um fato esperado que nesses períodos os incentivos e suas respostas à aquisição de tais bens adquiram uma proporção tal que possa ser caracterizado como uma febre consumista de TVs. No entanto, agora surge um elemento novo que passa a receber destaque crescente na decisão do consumidor na hora de escolher que tipo de televisor adquirir: plasma ou cristal líquido (LCD - liquid cristal display)?

As opções são as mais diversas e com o real valorizado a redução dos preços veio mais rápida, contribuindo para que o consumidor (não, necessariamente, tão abastado, dada a diversa gama de financiamentos disponíveis) possa enobrecer sua sala com TVs de última geração. Em períodos como o da Copa do Mundo do Futebol, a tendência é de que o preço desses produtos tenda a se elevar, mas segundo previsão da Fundação Instituto de Pesquisas

\footnotetext{
* Mestrando em Desenvolvimento Econômico pela Universidade Federal do Paraná (UFPR) e Membro do Grupo de Estudos em Economia Industrial (GEEIN). Endereço eletrônico: wdspereira@yahoo.com.br

** Mestrando em Desenvolvimento Econômico pela UFPR. Endereço eletrônico: jfelipealmeida@hotmail.com

*** Doutor em Economia (IE/UFRJ). Professor do Programa de Pós-Graduação em Desenvolvimento Econômico PPGDE/UFPR. Endereço eletrônico: waltershima@ufpr.br

35 "As características do futebol e os atributos da TV digital fazem um casamento perfeito", disse Dominik Schmid, diretor da Infront, empresa contratada pela Fifa para a transmissão televisiva e a comercialização dos direitos da Copa do Mundo de 2006. Fonte: VEJA on-line. Edição 1944. 22 de fev. 2006.
} 
Econômicas (FIPE-USP) a expectativa é que os aparelhos de TV fiquem 18,4\% mais baratos até meados de 2007. Adicionalmente, quando comparados os preços de maio em relação a abril, verificou-se uma evolução decrescente, dado o efeito câmbio que delineou o mesmo perfil para outros casos de produtos eletrônicos. Não obstante, nas semanas próximas ao início do campeonato, a FIPE registrou alta nos preços de televisores, em torno de 4,7\%. Entre março e maio foram comercializadas mais TVs de plasma e LCD que em todo o ano passado. Para o presidente da Eletros, Paulo Saab, a expectativa é vender cerca de 230 mil aparelhos no Brasil. A estimativa é que, em dez anos, essa reviravolta terá gerado vendas de 200 bilhões de reais - entre aparelhos receptores, transmissores e conversores devido, sobretudo, à expansão do uso da TV digital pelo mundo.

Além de já ter conquistado lugar de destaque entre os sonhos de consumo de grande parte dos indivíduos, os televisores de plasma e LCD ainda detêm uma característica decorativa, um importante elemento que lhe concede vantagens na concorrência com os seus substitutos próximos. Com esse novo produto recupera-se o sentido do design conforme exposto por Silverstone, R. \& Haddon, L. (1996) ${ }^{36}$. Segundo esses autores o design tem três dimensões inter-relacionadas. A primeira se relaciona ao objeto em si, que busca ter alguma utilização. Nessa dimensão há uma intensa relação entre uma série de atores tais como, engenheiros, empresários, vendedores, jornalistas, etc. em que se definem as novas possibilidades da tecnologia relacionada. Nessa dimensão, há um relacionamento simbiótico entre estética e inovação técnica, no sentido de que em última instancia, busca-se a definição de um objeto domesticável (que pode ser adicionado aos demais objetos correntes dos usuários); sendo aceito do ponto de vista estético (comodidade, agradabilidade) e tendo uma ampla difusão. Portanto, produção e design são inseparáveis. A segunda dimensão se relaciona à construção do usuário. Trata-se de identificar um processo de design por meio do que o usuário esteja integrado no hardware e software. Há um processo de learning-by-adapting em que o produtor busca sua satisfação profissional adaptando o produto às suas reais funções, ou seja, o designer quer que o seu design seja aceito pelo usuário e o usuário, além disso, quer que a máquina cumpra o seu objetivo. Obviamente, não se trata de um processo fácil, porque implica um certo grau de conflito incerto, como é corrente nos processos de aprendizado em geral. Do ponto de vista das organizações existem diferentes grupos envolvidos no design que

36 Mansell, Robin. Communication by Design the Politics of Information and Communication Technologies. Cap 2: Silverstone, Roger \& Haddon, Leslie. Design and the Domestication of Information and Communication Technologies: Technical Change and Everyday Life.

108

Economia \& Tecnologia - Ano 02, Vol. 05 - Abr./Jun. de 2006 
têm percepções diferentes de quem são os diferentes usuários e eles podem insistir que suas visões sejam as corretas. Portanto, o processo de configuração do artefato é político, na medida em que é necessário ter claro que usuários não são usuários técnicos. Trata-se de um sentido mais amplo dos usuários como integrante da relação com o artefato, não de uma forma técnica. Tratam-se da interação usuário/aparelho e satisfação. A terceira dimensão se relaciona à captura do usuário. Trata-se da criação de uma política organizacional complexa que envolve o consumidor e a mobilização de agentes industriais e comerciais de forma que os princípios que definem o produto possam ter um amplo caminho. Estes agentes incluem: organização de produtores, fontes externas de financiamento, fornecedores de produtos complementares, distribuidores e instaladores, etc. que estão envolvidos no pré-lançamento, ou teste ou pesquisa de mercado.

Assim, como esse processo de concorrência é centrado na diferenciação positiva que o consumidor atribui ao aparelho de TV, retomemos a grande dúvida sobre que tipo de tecnologia adquirir. A resposta para a questão deve vir acompanhada de algumas especificações acerca de cada caso e como estes influenciam o processo decisório do consumidor.

O cristal líquido ou LCD já é um velho conhecido de muitos, pois ele está presente na tela de monitores de computador, laptops e câmeras digitais. Como bem explicou Pereira ${ }^{37}$, as telas de plasma possuem um gás que, ao passar por um processo de ionização, assume o estado de plasma, também conhecido como o quarto estado da matéria. O plasma gera então raios ultravioleta, que atingem a superfície externa da tela, formando a imagem. Já as TVs de LCD têm uma lâmpada de luz branca (também chamada de backlight), cuja luminosidade é filtrada pelos cristais líquidos da tela.

Muito tem sido dito a respeito das diferenças ou das vantagens versus desvantagens na aquisição de um ou outro tipo de televisor, mas um importante fator é até que ponto os consumidores são capazes de perceber tais características divergentes. A tecnologia LCD recebe apostas como promissora porque detém características que superariam o plasma num futuro não muito distante. O fato é que a superioridade do LCD só poderia ser assimilada como superior quando melhorias na qualidade de transmissão e gravação de imagens ocorrerem, sobretudo, com a efetivação e expansão do uso da TV digital. Ou seja, aqueles que foram contaminados pela febre de consumo da Copa do Mundo do Futebol podem não ter,

\footnotetext{
${ }^{37}$ Plasma ou LCD? Eis a questão. Estado do Paraná - 31/05/2006.
} 
ainda, uma capacidade formada para perceber as vantagens do LCD. Contudo, tais TVs são mais leves que as de plasma e consomem menos energia, fatores que possivelmente serão perceptíveis ao consumidor.

Apesar de ambas as tecnologias serem incipientes, de certa forma, e, portanto, ainda deterem problemas, existem alguns fatores que têm obstruído uma maior velocidade no crescimento do consumo de televisores de LCD em relação aos de plasma. Alguns tipos de movimentos na imagem acabavam por deixar faixas escuras (rastros ou ghosts) na tela ou mesmo imagens estáticas não conseguiam se manter no visor (latência ou burn-in), mas, muitos dos avanços diários no desenvolvimento de tecnologias têm conseguido resolver alguns desses problemas, ainda que permaneçam outros ${ }^{38}$. Tais elementos dificultam o destaque dos televisores de LCD em relação aos seus substitutos próximos. O plasma continua a obter mais aceitação por dois fatores: primeiro, seu custo, e, por conseqüência seu preço, ainda é menor ${ }^{39}$; segundo, os televisores superiores a 46 polegadas só têm sido produzidos à base da tecnologia do plasma. No quesito expansão do consumo de massa, esses são fatores preponderantes.

O barateamento do LCD e o aumento de suas telas dependem da redução do desperdício ao se cortar as placas de cristal líquido com que são feitos os aparelhos de televisão. Em relação aos preços dos aparelhos que incorporam o LCD, já vem ocorrendo uma queda, e isso é uma questão de tempo para o aprimoramento da tecnologia. A resolução e a nitidez da imagem tem se mostrado superior nos modelos que adotam o cristal líquido (LCD) quando comparado com os televisores de plasma. Uma reportagem do jornal $\mathrm{O}$ Globo $^{40}$ apresentou as duas subcategorias do plasma em relação à definição da imagem: a stand definition, com resolução de 480 linhas, na qual a transmissão chega a 1080 linhas, ou seja, forma-se um gargalo, que acaba denegrindo a imagem - e o plasma com painel high definition, com resolução de 720 linhas, perfeita para transmissão de TV digital.

Segundo Alessandra de Macedo, técnica do ProTeste, o consumidor não deve se iludir com a compra de uma televisão tão cara porque o sistema tecnológico brasileiro da TV aberta ainda é analógico e isso pode causar distorções nas imagens. Na luta travada entre as

\footnotetext{
38 Uma das empresas que segue apostando no plasma, a LG, divulgou que já usa, em seus aparelhos, a tecnologia Orbiter, que gera uma vibração imperceptível na tela, evitando o problema de burn-in.

${ }^{39}$ Uma televisão que chegava a custar 30.000 reais em 2003 agora pode ser encontrada por menos de 9.000, numa redução de mais de $200 \%$. Uma razão para isso é que o Brasil já produz telas de plasma, que representam entre 60\% e 70\% do preço final do produto. Fonte: VEJA on-line. Edição 1944. 22 de fevereiro de 2006.

40 "Vendas de TVs de plasma e LCD continuam em disparada". O Globo - 26/05/2006.
} 
empresas defensoras de cada uma das tecnologias, temos, segundo reportagem do jornal Valor Econômico ${ }^{41}$, de um lado os ferrenhos defensores do plasma, como a Panasonic, enquanto no grupo adversário jogam os entusiastas do LCD, entre eles a Sharp e a Sony. Hoje, quem controla o mercado brasileiro de TVs de plasma é a LG, que assumiu a dianteira com uma política agressiva de preços.

Ao compararmos o perfil do consumidor brasileiro em relação ao chinês no que diz respeito à diferenciação entre televisores de LCD e plasma e às possibilidades de acesso (compra) dos mesmos, vê-se que há muito no que evoluir. Ao voltar de uma missão na China em 2005, Antônio Barros de Castro, diretor de planejamento do BNDES, argumentou que os televisores que estão nas prateleiras das lojas chinesas são, via de regra, de cristal líquido ${ }^{42}$. Para os chineses, o plasma é algo superado e os preços não ultrapassam dois mil dólares.

Apesar dos problemas que ainda estão presentes e por serem resolvidos nos dois padrões (plasma e LCD), os consumidores brasileiros desejosos de televisores de alta definição não têm deixado de responder aos incentivos do marketing ferrenho que as lojas especializadas tem feito nos últimos tempos para aumentar as suas vendas. A maior rede de varejo de eletrodomésticos no Brasil realizou uma promoção recente em que a compra de uma TV de plasma de 42 polegadas, no valor de $\mathrm{R} \$ 7980$, dava o direito de adquirir uma outra por somente um real, caso a seleção brasileira ganhasse a Copa do Mundo do Futebol. Dois mil desses televisores foram vendidos em sete dias. Como resposta ao desafio da competição, outras redes de varejo não deixaram de aumentar seus estoques desse tipo de produto, tal como daqueles tradicionais.

Não tem sido difícil verificar que as transformações tecnológicas dos televisores de alta tecnologia estão cada vez mais velozes e, a partir desse processo, dispostas a alterar fortemente a decisão do consumidor, com a tendência da redução ainda maior dos preços num futuro não distante. Mas, é importante lembrar que no mercado existem, também, outras tecnologias (por exemplo, wireless e TV transmitida via Internet) que, a partir de suas trajetórias evolutivas, proporcionarão outros rearranjos nas relações de produção e consumo.

41 “Tecnologia põe fabricantes em lados opostos". Valor Econômico - 07/10/2005.

42 "Os eletrodomésticos à venda nos supermercados de Xangai não existem nas prateleiras dos supermercados brasileiros. Lá, os televisores, em regra, são de cristal líquido. Plasma é uma solução superada. É tudo da maior qualidade. Telas enormes, planas, tudo elegantérrimo e vai ver o preço, é no máximo US\$2 mil. A China produz o que há de mais avançado". Entrevista concedida ao jornal Valor Econômico em - 07/10/2005. 
